\title{
Update: Ongoing Zika Virus Transmission - Puerto Rico, November 1, 2015-April 14, 2016
}

\author{
Emilio Dirlikov, PhD ${ }^{1,2}$; Kyle R. Ryff, MPH${ }^{1}$; Jomil Torres-Aponte, $\mathrm{MS}^{1}$; Dana L. Thomas, MD ${ }^{1,3}$; Janice Perez-Padilla, MPH ${ }^{4}$; Jorge Munoz-Jordan, PhD ${ }^{4}$; \\ Elba V. Caraballo, $\mathrm{PhD}^{4}$; Myriam Garcia ${ }^{5,6}$; Marangely Olivero Segarra, MS 5,6 ; Graciela Malave ${ }^{5,6}$; Regina M. Simeone, $\mathrm{MPH}^{7}$; \\ Carrie K. Shapiro-Mendoza, $\mathrm{PhD}^{8}$; Lourdes Romero Reyes ${ }^{9}$; Francisco Alvarado-Ramy, $\mathrm{MD}^{10}$; Angela F. Harris, $\mathrm{PhD}^{11}$; Aidsa Rivera, MSN ${ }^{4}$; \\ Chelsea G. Major, $\mathrm{MPH}^{4,12}$; Marrielle Mayshack ${ }^{1,12}$; Luisa I. Alvarado, MD ${ }^{13}$; Audrey Lenhart, PhD ${ }^{14}$; Miguel Valencia-Prado, MD ${ }^{15}$; \\ Steve Waterman, MD ${ }^{4}$; Tyler M. Sharp, $\mathrm{PhD}^{4}$; Brenda Rivera-Garcia, DVM ${ }^{1}$
}

\section{On April 29, 2016, this report was posted as an MMWR Early Release on the MMWR website (http://www.cdc.gov/mmwr).}

Zika virus is a flavivirus transmitted primarily by Aedes species mosquitoes, and symptoms of infection can include rash, fever, arthralgia, and conjunctivitis $(1) .^{*}$ Zika virus infection during pregnancy is a cause of microcephaly and other severe brain defects (2). Infection has also been associated with Guillain-Barré syndrome (3). In December 2015, Puerto Rico became the first U.S. jurisdiction to report local transmission of Zika virus, with the index patient reporting symptom onset on November 23, 2015 (4). This report provides an update to the epidemiology of and public health response to ongoing Zika virus transmission in Puerto Rico. During November 1, 2015-April 14, 2016, a total of 6,157 specimens from suspected Zika virus-infected patients were evaluated by the Puerto Rico Department of Health (PRDH) and CDC Dengue Branch (which is located in San Juan, Puerto Rico), and 683 (11\%) had laboratory evidence of current or recent Zika virus infection by one or more tests: reverse transcription-polymerase chain reaction (RT-PCR) or immunoglobulin $\mathrm{M}$ (IgM) enzyme-linked immunosorbent assay (ELISA). Zika virus-infected patients resided in 50 (64\%) of 78 municipalities in Puerto Rico. Median age was 34 years (range $=35$ days -89 years). The most frequently reported signs and symptoms were rash $(74 \%)$, myalgia (68\%), headache (63\%), fever (63\%), and arthralgia (63\%). There were $65(10 \%)$ symptomatic pregnant women who tested positive by RT-PCR or IgM ELISA. A total of 17 (2\%) patients required hospitalization, including $5(1 \%)$ patients with suspected Guillain-Barré syndrome. One $(<1 \%)$ patient died after developing severe thrombocytopenia. The public health response to the outbreak has included increased laboratory capacity to test for Zika virus infection (including blood donor screening), implementation of enhanced surveillance systems, and prevention activities focused on pregnant women. Vector control activities include indoor and outdoor residual spraying and reduction of mosquito breeding environments focused around pregnant women's homes. Residents of and travelers to Puerto Rico should continue to employ mosquito

\footnotetext{
${ }^{*}$ http://www.cdc.gov/zika/.
}

bite avoidance behaviors, take precautions to reduce the risk for sexual transmission (5), and seek medical care for any acute illness with rash or fever.

\section{Epidemiologic Surveillance}

In response to the introduction of Zika virus, $\mathrm{PRDH}$ and CDC Dengue Branch incorporated Zika virus case reporting and diagnostic testing into existing dengue and chikungunya virus surveillance systems and developed a laboratory-based Passive Arboviral Diseases Surveillance System. ${ }^{\dagger}$ Health providers submit serum specimens to $\mathrm{PRDH}$ from patients with a clinical suspicion of Zika, chikungunya, or dengue virus infection using a case report form. ${ }^{\$}$ Depending on the number of days between onset of illness and specimen collection, specimens are tested for the three arboviruses by a Trioplex RT-PCR assay, for evidence of Zika and dengue virus infection by IgM ELISA, or by both assays (4). ${ }^{9}$ Zika virus-infected patients were defined by positive results from either RT-PCR (confirmed) or IgM ELISA with negative dengue virus IgM ELISA (presumptive positive). Zika virus testing has been incorporated into the Sentinel Enhanced Dengue Surveillance System, which tests specimens from all febrile patients treated at either one outpatient clinic or one hospital emergency department in Ponce. Tissue and blood specimens collected during autopsy from patients who died after an acute febrile illness are tested for Zika virus infection through the Enhanced Fatal Acute Febrile Illness Surveillance System. ${ }^{* *}$ Following CDC interim guidance (๑), symptomatic pregnant women are tested using the diagnostic algorithm, and asymptomatic pregnant women are tested for evidence of Zika and dengue virus infection by IgM ELISA. Initiated in February 2016, the Guillain-Barré syndrome Passive Surveillance System allows health providers from across the

\footnotetext{
$\dagger^{\dagger}$ http://www.salud.gov.pr/Sobre-tu-Salud/Pages/Condiciones/Zika.aspx.

$\$_{\mathrm{http}}$ //www.salud.gov.pr/Sobre-tu-Salud/Documents/NEW\%20 Arbovirus\%20Case\%20Investigation\%20Form\%20-\%20March\%2029\%20 2016.pdf.

http://www.fda.gov/\%20EmergencyPreparedness/Counterterrorism/ MedicalCountermeasures/MCMIssues/ucm485199.htm.

** The Enhanced Fatal Acute Febrile Illness Surveillance System is co-operated by PRDH, Institute of Forensic Sciences of Puerto Rico, and CDC.
} 
island to report clinically suspected Guillain-Barré syndrome cases by sending a case report form and serum specimen to PRDH. ${ }^{\dagger \dagger}$ Specimens from patients with suspected GuillainBarré syndrome are tested by both RT-PCR and IgM ELISA for all three arboviruses. Diagnostic test results are managed through an integrated data management system. Results are reported to providers, and aggregate data are available online in a weekly arboviral report. $\$ \$$

During November 1, 2015-April 14, 2016, specimens from 6,157 suspected arbovirus-infected patients were evaluated and $683(11 \%)$ were either laboratory-confirmed or presumptive positive for Zika virus infection (Table). Of these 683 Zika virus laboratory confirmed or presumptive patients, 581 (85\%) were confirmed by RT-PCR, 73 (11\%) were presumptive positive by IgM ELISA, and 29 (4\%) were positive by both RT-PCR and IgM ELISA. Dengue, chikungunya, or unspecified flavivirus infection was identified in 110 (2\%), 61 (1\%), and $32(<1 \%)$ suspected arbovirus-infected patients, respectively. No patients with evidence of coinfection with Zika, dengue, or chikungunya viruses were identified by RT-PCR. Of all identified Zika virus-infected patients, 646 (95\%) were reported to the Passive Arboviral Diseases Surveillance System. Thirty-two (5\%) Zika virus-infected patients were reported through the Sentinel Enhanced Dengue Surveillance System. Five (1\%) suspected cases of Guillain-Barré syndrome reported to the Guillain-Barré syndrome Passive Surveillance System were presumptive positive for Zika virus infection, and two had unspecified flavivirus infection.

Weekly Zika virus disease case counts gradually increased since late November 2015, whereas incidence of dengue and chikungunya cases remained comparatively low (Figure 1). Zika virus-infected patients were reported from $50(64 \%)$ of the 78 total municipalities (Figure 2); 146 (21\%) patients were residents of the San Juan metropolitan area. Among all identified Zika virus-infected patients, 436 (64\%) were female, and median age was 34 years (range $=35$ days -89 years) . The most frequently reported signs and symptoms were rash (74\%), myalgia (68\%), headache $(63 \%)$, fever $(63 \%)$, and arthralgia (63\%). Thrombocytopenia (defined as blood platelets levels $<100,000$ cells $/ \mathrm{mm}^{3}$ ) was reported in nine (1\%) cases. Sixty-five (10\%) symptomatic pregnant women were Zika virus-infected patients. Seventeen (2\%) patients required hospitalization, including five $(1 \%)$ suspected Guillain-Barré syndrome cases. In one $(<1 \%)$ identified

\footnotetext{
$¥ \dagger$ Patients from across the island with clinical suspicion of Guillain-Barré syndrome can be reported to PRDH (http://www.salud.gov.pr/Sobre-tu-Salud/ Documents/ingl\%c3\%a9s.pdf).

$\$ \$$ http://www.salud.gov.pr/Estadisticas-Registros-y-Publicaciones/Pages/ Informe-Arboviral.aspx.
}

TABLE. Demographic characteristics, clinical course, and signs and symptoms of patients* with Zika virus disease $(N=683)-$ Puerto Rico, November 1, 2015-April 14, 2016

\begin{tabular}{lr}
\hline Characteristic & No. of patients (\%) \\
\hline History of recent travel ${ }^{\dagger}$ & $4(1)$ \\
Female & $436(64)$ \\
Pregnant & $65(10)$ \\
Hospitalized & $17(2)$ \\
Suspected GBS & $5(1)$ \\
Thrombocytopenia" & $9(1)$ \\
Deaths & $1(<1)$ \\
Signs and symptoms** & \\
Rash & $505(74)$ \\
Myalgia & $462(68)$ \\
Headache & $433(63)$ \\
Fever & $429(63)$ \\
Arthralgia & $428(63)$ \\
Eye pain & $350(51)$ \\
Chills & $344(50)$ \\
Sore throat & $233(34)$ \\
Petechiae & $213(31)$ \\
Conjunctivitis & $137(20)$ \\
Nausea/Vomiting & $123(18)$ \\
Diarrhea & $115(17)$ \\
\hline Abbreviation: GBS Gulla
\end{tabular}

Abbreviation: GBS = Guillain-Barré syndrome.

* Patients were aged 35 days -89 years (median age $=34$ years).

† Travel outside of Puerto Rico and the United States in the 14 days before illness onset.

$\S$ All GBS patients were hospitalized.

" Defined as blood platelets levels $<100,000$ cells $/ \mathrm{mm}^{3}$.

** Signs and symptoms were reported by the patients' clinician.

Zika virus-associated case, the patient died of complications related to severe thrombocytopenia.

To ensure the safety of the blood supply, Puerto Rico imported all blood products from the United States during March 5April 14 (7). On April 2, blood collection resumed with donor screening using a Food and Drug Administration-approved Zika virus investigational nucleic acid detection test (Roche Molecular Systems, Inc., Pleasanton, California). Emergency blood imports ended on April 15. During April 2-14, nine (<1\%) of 1,910 screened donated blood units had positive test results. These units were removed from the blood supply, and testing is pending to confirm presumptive Zika virus infection.

\section{Public Health Response}

Through the Zika Active Pregnancy Surveillance System, Zika virus-infected pregnant women and their offspring are monitored for adverse maternal, fetal, neonatal, infant, and child health outcomes. 99 Surviving offspring across the island will be referred to the Children with Special Health Care Needs program for developmental surveillance and coordination of specialized services, as needed, up to age 3 years. The Birth Defects Surveillance System ${ }^{* * *}$ will identify newborns with congenital

\footnotetext{
I9 Zika Active Pregnancy Surveillance System is co-operated by PRDH and CDC.

*** PRDH routinely monitors birth defects throughout the island through the Birth Defect Surveillance System.
} 
FIGURE 1. Cases of Zika virus disease $(n=683)$, dengue $(n=110)$, and chikungunya $(n=61)$ by week of onset of patient's illness - Puerto Rico, November 1, 2015-April 14, 2016

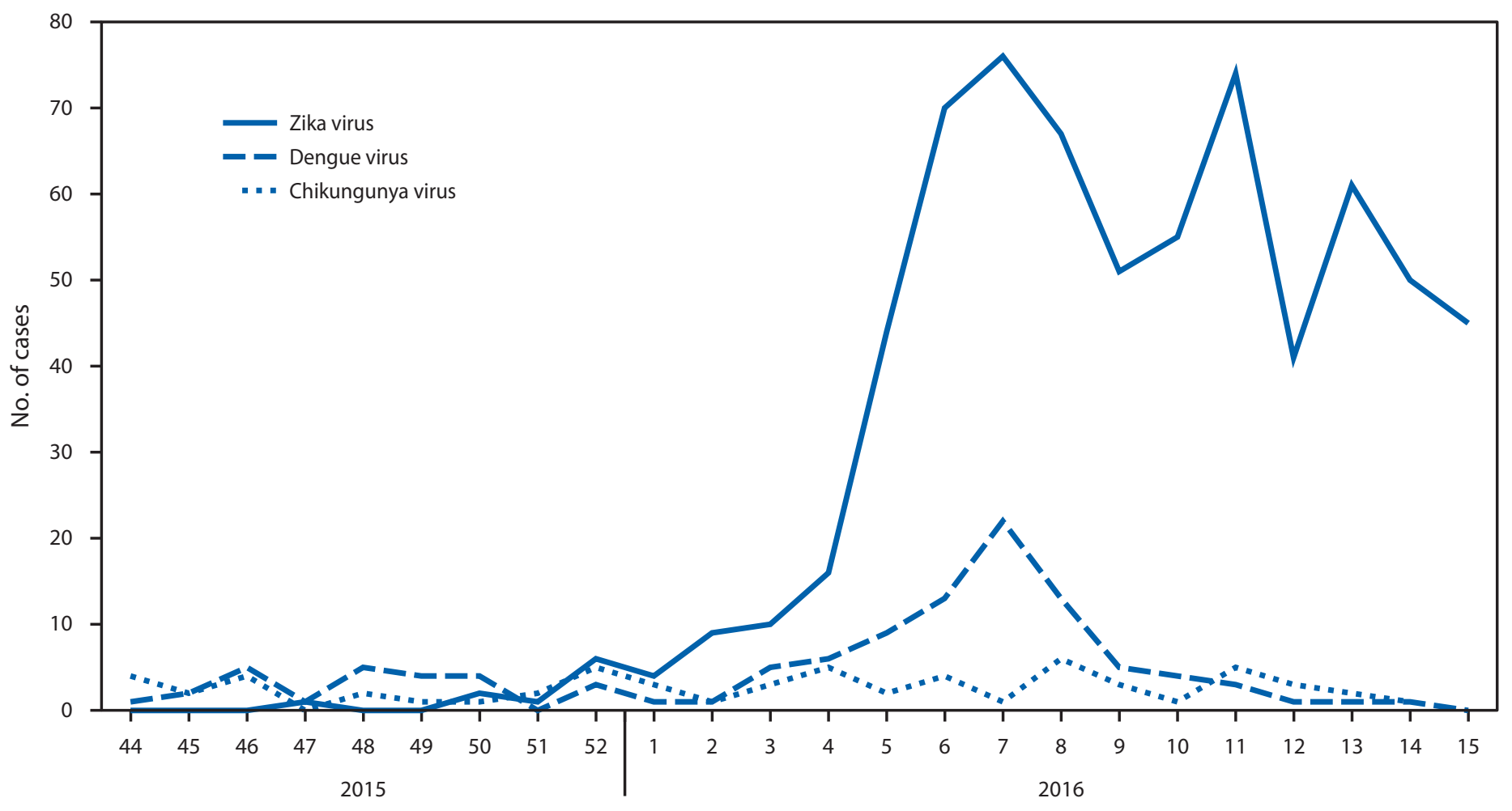

Epidemiologic week

FIGURE 2. Municipality of residence of persons with Zika virus disease $(n=679)^{*}$ - Puerto Rico, November 1, 2015-April 14, 2016

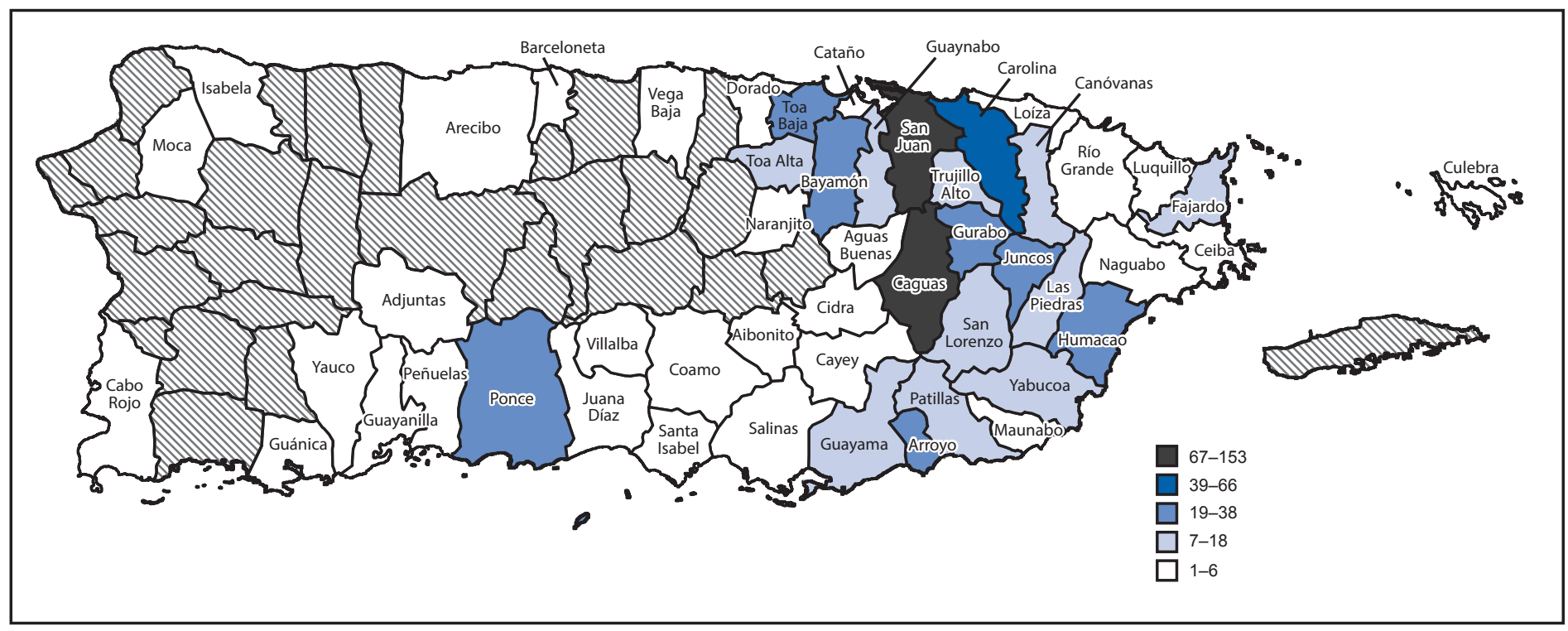

* Four cases were reported with unknown municipality of residence. 
microcephaly, including those born to women infected with Zika virus during pregnancy, and refer all cases to Avanzando Juntos, Puerto Rico's Early Intervention Services System.

With CDC's assistance, PRDH has also implemented comprehensive strategies to prevent Zika virus transmission. Health messaging, including posters and electronic monitors, have been implemented and health education materials are available at various locations, including health care facilities and ports of entry. Community intervention strategies have focused on pregnant women. PRDH has worked closely with Women, Infants, and Children (WIC) clinics, where $90 \%$ of Puerto Rican pregnant women received services in 2015 (Dana Miró Medina, WIC Puerto Rico, personal communication, 2016). As of April 13, a total of 13,351 pregnant women participated in Zika virus educational orientations offered by WIC clinics. PRDH and the CDC Foundation financed the purchase and delivery of Zika Prevention Kits, which include locally adapted health information, mosquito repellent, a bed net, larvicidal tablets (tablets placed in water sources where mosquitoes might breed that prevent larvae from maturating into adults), and condoms. In addition, to reduce the risk for unintended pregnancies with adverse fetal outcomes related to Zika virus infection, the response includes increasing the availability of contraceptives (8).

During February-March, an insecticide resistance study of Aedes aegypti mosquitoes was conducted to develop vector control strategies, such as truck-mounted, ultra-low volume spraying and indoor and outdoor residual spraying. Mosquitoes from across Puerto Rico were tested using the CDC bottle bioassay to determine insecticide susceptibility, particularly against pyrethroids. Results indicated a high degree of geographical variation with respect to susceptibility to insecticides, and deltamethrin was identified as the most suitable pyrethroid candidate for use in vector control programs (data not shown). Insecticide susceptibility surveillance is ongoing.

A home-based vector control program focused on pregnant women is underway. Women are contacted through WIC clinics, and are offered source reduction services (e.g., removal of water containers that can serve as mosquito breeding sites), larvicide application, and indoor and outdoor residual spraying using deltamethrin. PRDH and CDC have collaborated with the Puerto Rico Department of Housing to incorporate these services into its vector control activities.

\section{Discussion}

Zika virus remains a public health challenge in Puerto Rico, and cases are expected to continue to occur throughout 2016. Building upon existing dengue and chikungunya virus surveillance systems, PRDH collaborated with CDC to establish a comprehensive surveillance system to characterize the incidence and epidemiology of Zika virus disease on the island. Expanded laboratory capacity

\section{Summary \\ What is already known about this topic?}

Zika virus transmission in Puerto Rico has been ongoing, with the first patient reporting symptom onset in November 2015. Zika virus infection is a cause of microcephaly and other severe birth defects. Zika virus infection has also been associated with Guillain-Barré syndrome.

What is added by this report?

During November 1, 2015-April 14, 2016, a total of 6,157 specimens from suspected Zika virus-infected patients from Puerto Rico were evaluated and 683 (11\%) had laboratory evidence of current or recent Zika virus infection. The public health response includes increased capacity to test for Zika virus, preventing infection in pregnant women, monitoring infected pregnant women and their fetus for adverse outcomes, controlling mosquitos, and assuring the safety of blood products.

What are the implications for public health practice?

Residents of and travelers to Puerto Rico should continue to employ mosquito bite avoidance behaviors, take precautions to reduce the risk for sexual transmission, and seek medical care for any acute illness with rash or fever. Clinicians who suspect Zika virus disease in patients who reside in or have recently returned from areas with ongoing Zika virus transmission should report cases to public health officials.

and surveillance provided timely availability of data, allowing for continuous analysis and adapted public health response. Following CDC guidelines, both symptomatic and asymptomatic pregnant women are tested for evidence of Zika virus infection. Information from the Zika Active Pregnancy Surveillance System will be used to raise awareness about the complications associated with Zika virus during pregnancy, encourage prevention through use of mosquito repellent and other methods, and inform health care providers of the additional care needed by women infected with Zika virus during pregnancy, as well as congenitally exposed fetuses and children. In addition, the prevalence of adverse fetal outcomes documented through this system can be compared with baseline rates as further evidence of associations between Zika virus infections and adverse outcomes, such as microcephaly (2).

The finding that women constitute the majority of cases might be attributable to targeted outreach and testing. The most common symptoms among Zika virus disease cases were rash, myalgia, headache, fever, and arthralgia, which are similar to the most common signs and symptoms reported elsewhere in the Americas (9). Although Zika virus-associated deaths are rare (10), the first identified death in Puerto Rico highlights the possibility of severe cases, as well as the need for continued outreach to raise health care providers' awareness of complications that might lead to severe disease or death. To ensure continued blood safety, blood collection resumed 
with a donor screening program for Zika virus infection, and all units screened positive are removed.

Residents of and travelers to Puerto Rico should continue to employ mosquito bite avoidance behaviors, including using mosquito repellents, wearing long-sleeved shirts and pants, and ensuring homes are properly enclosed (e.g., screening windows and doors, closing windows, and using air conditioning) to avoid bites while indoors. ${ }^{\dagger \dagger}$ To reduce the risk for sexual transmission, especially to pregnant women, precautions should include consistent and proper use of condoms or abstinence (5). Such measures can also help avoid unintended pregnancies and minimize risk for fetal Zika virus infection (G). Clinicians who suspect Zika virus disease in patients who reside in or have recently returned from areas with ongoing Zika virus transmission should report cases to public health officials.

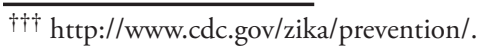

${ }^{1}$ Office of Epidemiology and Research, Puerto Rico Department of Health; ${ }^{2}$ Epidemic Intelligence Service, Division of Scientific Education and Professional Development, CDC; ${ }^{3}$ Division of State and Local Readiness, Office of Public Health Preparedness and Response, CDC; ${ }^{4}$ Division of Vector-Borne Diseases, National Center for Emerging and Zoonotic Infectious Diseases, CDC; ${ }^{5}$ Biological and Chemical Emergencies Laboratory, Office of Public Health Preparedness and Response, Puerto Rico Department of Health; ${ }^{6}$ Public Health Laboratory, Puerto Rico Department of Health; ${ }^{7}$ Division of Congenital and Developmental Disorders, National Center on Birth Defects and Developmental Disabilities, CDC; ${ }^{8}$ Division of Reproductive Health, National Center for Chronic Disease Prevention and Health Promotion, CDC ; ${ }^{9}$ Puerto Rico Women, Infants, and Children Program; ${ }^{10}$ Division of Global Migration and Quarantine, National Center for Emerging and Zoonotic Infectious Diseases, CDC; ${ }^{11}$ Bill \& Melinda Gates Foundation, Seattle, WA; ${ }^{2}$ Office for State, Tribal, Local, and Territorial Support, CDC; ${ }^{13}$ Ponce Health Sciences University-Saint Luke's Episcopal Hospital Consortium, Puerto Rico; ${ }^{14}$ Division of Parasitic Diseases and Malaria, Center for Global Health, CDC; ${ }^{15}$ Puerto Rico Birth Defects Surveillance and Prevention System, Puerto Rico Department of Health.

Corresponding author: Emilio Dirlikov, Zika@salud.gov.pr, 787-765-2929.

\section{Acknowledgment}

Kathryn Conlon, PhD, National Center for Environmental Health, CDC.

\section{References}

1. Petersen LR, Jamieson DJ, Powers AM, Honein MA. Zika virus. N Engl J Med 2016;374:1552-63. http://dx.doi.org/10.1056/NEJMra1602113

2. Rasmussen SA, Jamieson DJ, Honein MA, Petersen LR. Zika virus and birth defects-reviewing the evidence for causality. N Engl J Med 2016. Epub April 13, 2016. http://www.nejm.org/doi/full/10.1056/ NEJMsr1604338

3. Cao-Lormeau VM, Blake A, Mons S, et al. Guillain-Barré syndrome outbreak associated with Zika virus infection in French Polynesia: a case-control study. Lancet 2016;387:1531-9. http://dx.doi.org/10.1016/ S0140-6736(16)00562-6

4. Thomas DL, Sharp TM, Torres J, et al. Local transmission of Zika virus-Puerto Rico, November 23, 2015-January 28, 2016. MMWR Morb Mortal Wkly Rep 2016;65:154-8. http://dx.doi.org/10.15585/ mmwr.mm6506e2

5. Oster AM, Russell K, Stryker JE, et al. Update: interim guidance for prevention of sexual transmission of Zika virus-United States, 2016. MMWR Morb Mortal Wkly Rep 2016;65:323-5. http://dx.doi. org/10.15585/mmwr.mm6512e3

6. Petersen EE, Polen KN, Meaney-Delman D, et al. Update: interim guidance for health care providers caring for women of reproductive age with possible Zika virus exposure-United States, 2016. MMWR Morb Mortal Wkly Rep 2016;65:315-22. http://dx.doi.org/10.15585/mmwr. $\mathrm{mm} 6512 \mathrm{e} 2$

7. Vasquez AM, Sapiano MR, Basavaraju SV, Kuehnert MJ, Rivera-Garcia B. Survey of blood collection centers and implementation of guidance for prevention of transfusion-transmitted Zika virus infection-Puerto Rico, 2016. MMWR Morb Mortal Wkly Rep 2016;65:375-8. http:// dx.doi.org/10.15585/mmwr.mm6514e1

8. Tepper NK, Goldberg HI, Bernal MI, et al. Estimating contraceptive needs and increasing access to contraception in response to the Zika virus disease outbreak-Puerto Rico, 2016. MMWR Morb Mortal Wkly Rep 2016;65:311-4. http://dx.doi.org/10.15585/mmwr.mm6512e1

9. Brasil P, Calvet GA, Siqueira AM, et al. Zika virus outbreak in Rio de Janeiro, Brazil: clinical characterization, epidemiological and virological aspects. PLoS Negl Trop Dis 2016;10:e0004636. http://dx.doi. org/10.1371/journal.pntd.0004636

10. Sarmiento-Ospina A, Vásquez-Serna H, Jimenez-Canizales CE, VillamilGómez WE, Rodriguez-Morales AJ. Zika virus associated deaths in Colombia. Lancet Infect Dis 2016;16:523-4. http://dx.doi.org/10.1016/ S1473-3099(16)30006-8 